\section{Vaccine boosters: Mandatory is not the only way, but it does seem to be an effective way}

\section{Accroître la couverture vaccinale : obligation n'est pas le seul moyen, mais on dirait qu'il marche}

We are particularly disappointed by the use of the term "authoritarian" as indicated recently for the new mandatory vaccination policy in France [1], and also by the concept of suppression of personal freedom that has been associated with such mandatory vaccination. People can only consider themselves to be fully free when they are fully aware of the consequences of their choices. Furthermore, in a community, the concept of individual freedom cannot be considered separately from respect for the rights of the other members of the community. For example, in Italy, where the new legislation on mandatory vaccination served as an example for the French legislation that it preceded by a few months there have been intense debates and further legislative changes [2].

We are aware that alternative means to legislation can help to increase vaccination coverage, but these are often strongly influenced by the media and by other non-scientifically supported information sources [3], which was particularly the case in Italy. Prior to the introduction of what is known as the Lorenzin Law (by Italian Health Minister, Beatrice Lorenzin), according to the autonomy guaranteed by constitutional reform, the Veneto Region decided to suspend the previously obligatory vaccinations (i.e. immunization against diphtheria, poliomyelitis, tetanus and hepatitis B). This resulted in significant reduction in vaccination coverage [4]. Then, the reintroduction and expansion of these national obligations rapidly reversed this downward trend, as confirmed by the most recent data (e.g., 4.42\% growth for the first dose of measles vaccination) $[5,6]$. Although we are fully in agreement with education and empowerment of the population as fundamental tools to support primary prevention, we share the perplexities expressed by others on the limited success of such strategies [7]. In France, the concept of freedom is expressed in their dictum "Liberté, Égalité, Fraternité", as a secular cornerstone of the Republic, and similarly in Italy, Article 32 of the Constitution states, "The
Republic protects health as a fundamental right of the individual and of importance to the community, and guarantees free healthcare for those in need. No one can be forced to undergo any specific health treatment, except when accorded by Law. The Law cannot under any circumstances violate the limits imposed by respect for the human person". History teaches us that mandatory vaccination "accorded by law" in many countries (including Italy) has been one of the most important instruments in the protection of Public Health [8].

Disclosure of interest: the authors declare that they have no competing interest.

\section{References}

[1] Laws are not the only way to boost, immunization. Nature 2018;553:24950. http://dx.doi.org/10.1038/d41586-018-00660-y.

[2] Capasso L, D'Alessandro D. Are two laws better than one in Italy? Compulsory vaccinations, double trouble. Press Med 2018;47:197-8 http://dx.doi.org/10.1126/science.aal1120.

[3] Wadman $M$. The riskiest vaccine? The one that is not given. Science 2017;80. http://dx.doi.org/10.1126/science.aal1120 [https://www.sciencemag.org/news/2017/04/riskiest-vaccine-one-not-given].

[4] Amendola A, Bubba L, Piralla A, Binda S, Zanetti A, Pariani E, et al. Surveillance and vaccination coverage of measles and rubella in Northern Italy. Hum Vaccin Immunother 2015;11:206-13. http://dx.doi.org/ $10.4161 /$ hv.35865

[5] Ministero della Salute. I dati nazionali al 2017 sulle coperture vaccinal dell'età pediatrica e dell'adolescente n.d. http://www.salute.gov.it/ portale/news/p3 2 _ 1 _ 1 1.jsp?

lingua=italiano\&menu=notizie\&p=dalministerosid=3348 [accessed May 3, 2018]

[6] Burioni R, Odone A, Signorelli C. Correspondence: Italy's policy shift on immunization. Nature 2018;555:30. http://dx.doi.org/10.1038/d41586018-02567-0.

[7] Kupferschmidt K. Can skeptical parents be persuaded to vaccinate? Science 2017;80. http://dx.doi.org/10.1126/science.aal1108.

[8] Plotkin SA, Orenstein WA, Offit PA. Plotkin's vaccines; 2017

Lorenzo Capasso ${ }^{1}$, Daniela D'Alessandro²

${ }^{1}$ University of Pavia, Department of Public Health, Experimental and Forensic Medicine, Via Forlanini, 2, Pavia, Italy

${ }^{2}$ Department of Civil Building Environmental Engineering, Rome, Italy

Correspondence: L. Capasso, University of Pavia, Department of Public Health, Experimental and Forensic Medicine, Via Forlanini, 2, Pavia,

lorenzo.capasso@unipv.it

Available online: 17 April 2019

https://doi.org/10.1016/j.lpm.2019.03.004

(c) 2019 Elsevier Masson SAS. All rights reserved. 